\title{
Stability analysis of Baishuihe landslide under the combined effect of reservoir and rainfall
}

\author{
Yi Liu ${ }^{1}$, Binbin Zhao ${ }^{1 *}$, Bin Liu ${ }^{1}$, Xiaoang Kong ${ }^{1}$, Zhi Yang ${ }^{1}$ \\ ${ }^{1}$ China Electric Power Research Institute Co., Ltd., Beijing, 100192, China.
}

\begin{abstract}
Reservoir drawdown and rainfall have important influence on bank landslides, but existing research on these two factors is too idealistic. A new reservoir drawdown model was proposed for the rapid drawdown stage based on the consideration of reduction, navigation and power generation. A rainfall model was proposed considering actural rainfall and rainfall time based on fifty years of daily rainfall data. At last, taking Baishuihe landslide as an example, the landslide stability was analyzed under the combined influenced of rainfall and reservoir drawdown. Results show that the Baishuihe landslide is mainly influenced by reservoir drawdown. The terminal reservoir drawdown model can reduce the effect of continuous decline of reservoir on landslide and the stability decreases about $0.7 \% \sim 1.2 \%$ compared with normal scenario. The reservoir drawdown model proposed in this paper is of significance to the reservoir operation in the Three Gorges Reservoir.
\end{abstract}

\section{Introduction}

The change of reservoir water level and rainfall are important factors inducing reservoir bank landslide [1-3]. At the beginning of the impoundment of the three Gorges Reservoir area, the decline rate of the reservoir water is strictly limited to less than $0.6 \mathrm{~m} / \mathrm{d}$. After ten years of steady operation of the reservoir water, the reservoir bank has basically adapted to the new periodic hydrogeological conditions. The maximum daily drop of $0.6 \mathrm{~m} / \mathrm{d}$ set in the previous period limits the benefit of the three Gorges Dam, so it is necessary to study the influence of increasing the decline rate of reservoir water level on the stability of landslide.

In recent years, the stability of landslide under the combined action of rainfall and reservoir water has been widely studied. Wang Li et al.[4], Zhang Guirong et al.[5], Wang Peng et al.[6] studied the stability of the landslide when the reservoir water decreased from $175 \mathrm{~m}$ to $145 \mathrm{~m}$ at a constant rate, and studied the influence of the decline rate on the stability of the landslide. Xiao Zhiyong et al. [7] analyzed the stability of the landslide when the reservoir water decreased intermittently from $175 \mathrm{~m}$ to $145 \mathrm{~m}$. The above research ignores the actual dispatching of reservoir water level and the distribution of rainfall, and two important influencing factors are oversimplified.

When considering the influence of reservoir water, many scholars take the decline rate of reservoir water as the starting point, and drop the reservoir water level from $175 \mathrm{~m}$ to $145 \mathrm{~m}$ at a constant rate, ignoring the duration of the decline of reservoir water. With the increase of the decline rate, the duration of reservoir water decline will be significantly reduced, and the duration is very important for shipping, power generation, flood control and so on. If the reservoir water decreases too fast from $175 \mathrm{~m}$, it will lead to the grounding of a large number of ships in the section from Chongqing Port to Fengdu, which will seriously affect the safe shipping of ships. At the same time, the consideration of rainfall is too rough, most of them take the extreme rainfall of a hydrological year as the rainfall condition, and the selection of rainfall loading time is greatly influenced by human factors $[8$, 9].

In this paper, taking Baishuihe landslide as an example, based on the actual reservoir water dispatching, a dispatching model for increasing the decline rate of reservoir water level is proposed, and according to the rainfall data of Zigui in the past 50 years, rainfall and rainfall loading time are fully considered. finally, the stability of Baishuihe landslide under different reservoir water decline rates and rainfall conditions is studied.

\section{Background of Baishuihe landslide}

Baishuihe landslide is located in Baishuihe Village, Shazhenxi Town, the south bank of the Yangtze River, according to the three Gorges Dam site $56 \mathrm{~km}$. The bank slope belongs to the broad and gentle valley of the Yangtze River, monoclinic bedding slope, which is distributed step by step along the Yangtze River. The landslide is $600 \mathrm{~m}$ long from north to south, $430 \mathrm{~m}$ wide from east to west, the area is about $21.5 \times 10^{4} \mathrm{~m}^{2}$, the average thickness is $30 \mathrm{~m}$, the total volume is about 645 $\times 104 \mathrm{~m} 3$, and the main sliding direction is $20^{\circ}$. It is a deep large loose accumulation landslide (figure 1). The underlying bedrock of the landslide is medium-thick layered siltstone and thin layer argillaceous siltstone in

\footnotetext{
* Corresponding author: 123zhaobinbin@163.com
} 
the Xiangxi formation $(\mathrm{J} 1 \mathrm{x})$ of the Lower Luo system, and the silty clay deposited in the Quaternary residual slope is intercalated with crushed stone (figure 2).

Baishuihe landslide has occurred obvious deformation since the trial operation of the water level of the three Gorges in June 2003, resulting in a transverse crack of about $300 \mathrm{~m}$ in the middle of the leading edge. In 2005, due to the widening construction of the highway along the river, the upper slope of the landslide slipped and the highway slope collapsed. At the end of June 2007 , there was a local slip of the accumulation body above the highway, with the leading edge of the highway as the leading edge, with a width of about $220 \mathrm{~m}$ from east to west, $120 \mathrm{~m}$ wide at the trailing edge, $100 \mathrm{~m}$ in length, $6 \mathrm{~m}$ in thickness and $100,000 \mathrm{~m} 3$ in volume. Onthe-spot investigation and professional monitoring show that the deformation intensifies from May to July each year, and tends to be stable from August to April of the following year. The landslide deformation is the largest at the initial stage of water impoundment. With the enhancement of the adaptive ability of the accumulation body, the accumulation body gradually adapts to the influence of reservoir water change and rainfall, and the annual deformation amplitude tends to decrease.

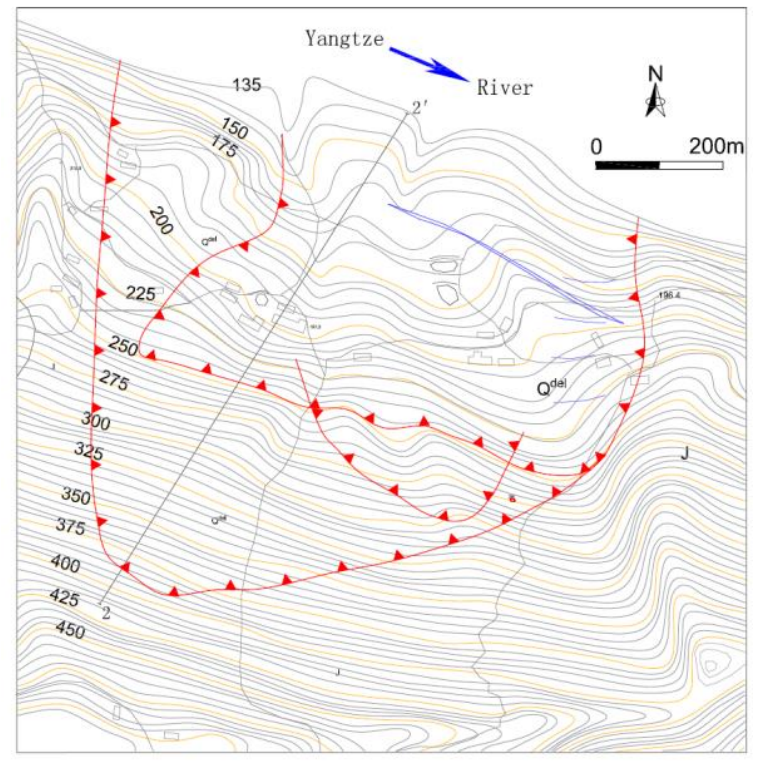

Fig. 1 Geological plane of Baishuihe landslide

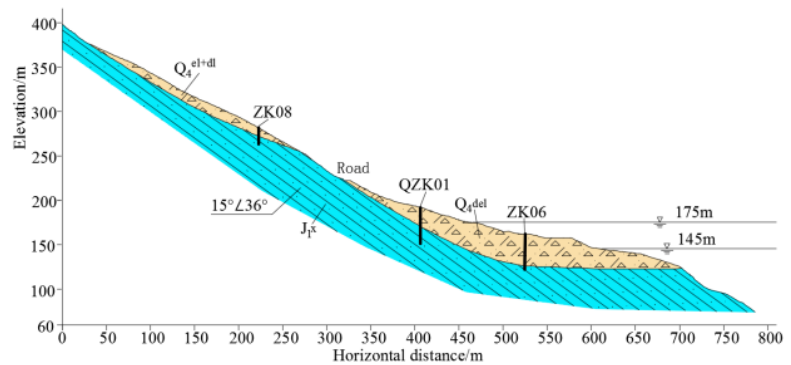

Fig. 2 Geological profile of Baishuihe landslide

\section{Reservoir water decline and rainfall model}

\subsection{Reservoir descending scheduling model}

The daily reservoir water level dispatching data from 2011 to 2016 are collected, and the average fitting of the reservoir water level data is carried out to obtain the actual dispatching model of the three Gorges reservoir area (figure 3). On the basis of this model, the influence of increasing the decline rate of reservoir water level on the stability of landslide is studied. After 8 years of complete operation, the reservoir bank has basically adapted to the current hydrogeological conditions, and due to the influence of leaching[10], the rock and soil mass in the lower part of the reservoir has a stronger adaptability to the change of reservoir water. Therefore, when increasing the decline rate of reservoir water level, there is a gradual process, that is, the initial water level of increasing the decline rate of reservoir water level needs to increase gradually from low to high. To ensure that the reservoir bank can fully adapt to the new environment.

As the low water level is not conducive to navigation and power generation, it is necessary to shorten the time of low water level as much as possible. At the same time, the continuous and rapid reduction of the reservoir water level will lead to the untimely discharge of groundwater in the landslide, resulting in greater hydrodynamic pressure, thus inducing the landslide. Therefore, this paper takes $155 \mathrm{~m}$ as the starting point to increase the decline rate of reservoir water level, in which the decline rate of $175 \mathrm{~m}-155 \mathrm{~m}$ section decreases according to the original rate, and the decline rate of $0.3,0.6,0.9,1.2$ and $1.5 \mathrm{~m} / \mathrm{d}$ is adopted in the section of $155 \mathrm{~m}-145 \mathrm{~m}$, respectively.

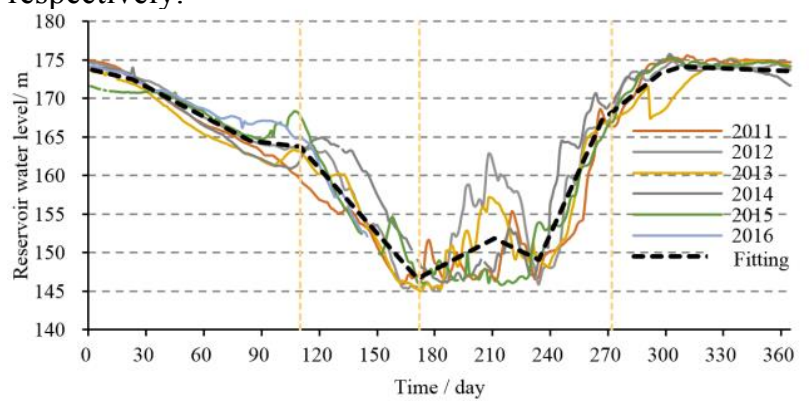

Fig. 3 The reservoir regulation of the Three Gorges Reservoir

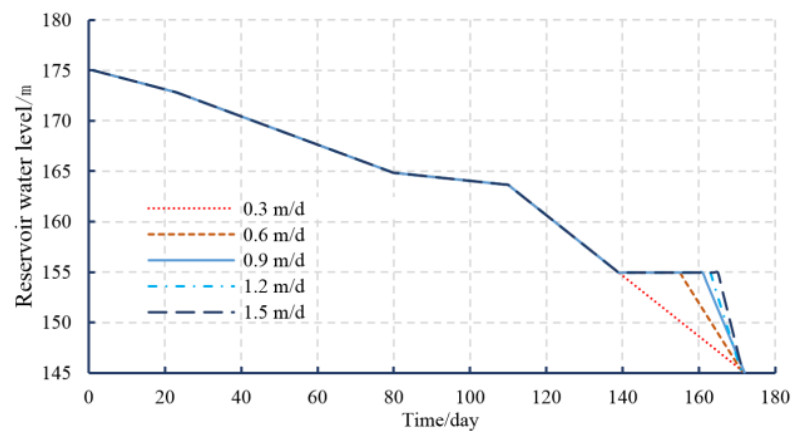

Fig. 4 Reservoir drawdown model 


\subsection{Rainfall distribution model}

At present, when considering the rainfall factors, the rainstorm model is mostly used, and the rainstorm includes the rainfall data in the flood season, which results in the obvious large rainfall value. At the same time, the loading time of rainstorm is relatively random, and the influence of human factors is great. Based on the above deficiencies, this paper sets the rainfall conditions according to the actual rainfall.

Statistics of rainfall data from 1960 to 2014 in Zigui area, calculate the cumulative rainfall in the interval of $1 \times 1,1 \times 6$ and 20 (figure 5), and select the maximum cumulative rainfall as the rainfall calculation parameter. According to the analysis of figure 5, the cumulative rainfall in Zigui area in 2002 was the highest, reaching $846.4 \mathrm{~mm}$, which was much higher than the average value of $418 \mathrm{~mm}$ in the past 55 years in Zigui area. Therefore, according to the rainfall value of $12002 \mathrm{~cm}$ 6ap20 section in 2002, two rainfall events, A (4Compact 235percusher 6) and B (6Universe 6percussion 10), were calculated, in which An accumulated rainfall $198.7 \mathrm{~mm}$ $154 \mathrm{~mm}$.

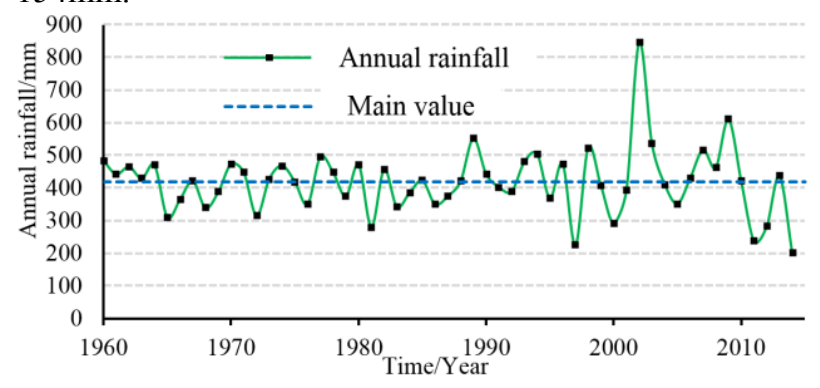

Fig. 5 The accumulated rainfall from $1 / 1$ to $6 / 20$ during 1960 2014 in Zigui County

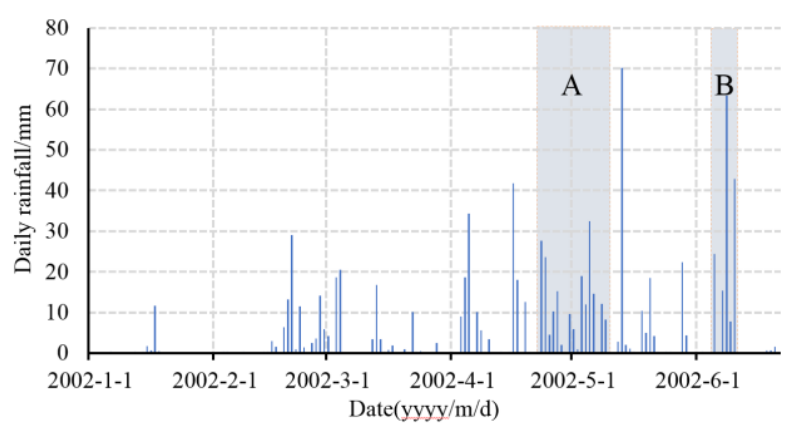

Fig. 6 Rainfall conditions in 1/1 6/20, 2002

\section{4 stability analysis.}

\subsection{Calculation model and selection of working conditions}

In this paper, based on the finite element software GeoStudio, the model is established in 2-2 'section, the element length is set to $3 \mathrm{~m}$, and the anisotropy of sliding material is ignored. Based on the saturated-unsaturated theory of rock and soil, the calculation parameters of unsaturated soil are determined according to the Van Genuchten soil-water characteristic empirical curve and saturated rock and soil parameters in SEEP/W module. The seepage field of landslide at different time is obtained by loading rainfall and changing the decline rate of reservoir water. Finally, the seepage field at different time is introduced into the SLOPE/W module, and the Morgenstern-Price method is used to calculate the stability. According to the parameters of similar rock and soil mass in the existing survey data, the saturated volume water content and permeability coefficient are determined by engineering geological analogy method and field investigation, and the saturated shear strength parameters of rock and soil mass are determined according to laboratory test[11]. The calculation parameters and calculation model are shown in figure 7.

The initial and boundary conditions: fixed the horizontal and vertical displacement at the bottom of the model, fixed the horizontal displacement on both sides of the model; the surface of the sliding body above $175 \mathrm{~m}$ is set as the rainfall infiltration boundary, below $175 \mathrm{~m}$ as the reservoir water infiltration boundary, and the bedrock is set as the impervious layer. Combined with the on-site investigation and monitoring data, the stable groundwater level of $175 \mathrm{~m}$ is taken as the initial groundwater level.

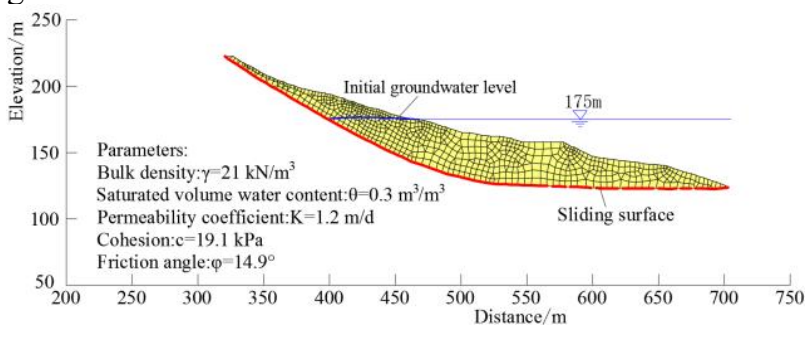

Fig. 7 Calculation model and parameters of Baishuihe landslide

According to the above analysis, the following working conditions are used for calculation (Table 1).

Table 1 Calculation conditions of Baishuihe landslide

\begin{tabular}{|c|c|c|c|}
\hline & $\begin{array}{l}\text { Descending } \\
\text { rate from } \\
155 \mathrm{~m} \text { to } \\
145 \mathrm{~m}\end{array}$ & Reservoir water decline model. & $\begin{array}{c}\text { Rainfall } \\
\text { model. }\end{array}$ \\
\hline A & $0.3 \mathrm{~m} / \mathrm{d}$ & $\begin{array}{l}\text { The reservoir water should be } \\
\text { considered according to the } \\
\text { actual dispatching. }\end{array}$ & \multirow{4}{*}{$\begin{array}{l}\text { Two } \\
\text { rainfall } \\
\text { events An } \\
\text { and B in } \\
\text { January } 1 \sim \\
6 / 20 \text { in } \\
2002 \text { were } \\
\text { taken as } \\
\text { rainfall } \\
\text { conditions. }\end{array}$} \\
\hline B & $0.6 \mathrm{~m} / \mathrm{d}$ & \multirow{3}{*}{$\begin{array}{l}\text { The reservoir water starts from } \\
175 \mathrm{~m} \text {, decreases to } 155 \mathrm{~m}(1- \\
139 \mathrm{~d}) \text { according to the actual } \\
\text { dispatching mode, then stabilizes } \\
\text { for a period of time, and then } \\
\text { decreases to } 145 \mathrm{~m} \text { at different } \\
\text { rates }(0.6,0.9,1.2,1.5) \\
\text { respectively. }\end{array}$} & \\
\hline $\mathrm{C}$ & $0.9 \mathrm{~m} / \mathrm{d}$ & & \\
\hline $\mathrm{E}$ & $1.5 \mathrm{~m} / \mathrm{d}$ & & \\
\hline $\mathrm{F}$ & $0.3 \mathrm{~m} / \mathrm{d}$ & $\begin{array}{l}\text { The reservoir water should be } \\
\text { considered according to the } \\
\text { actual dispatching. }\end{array}$ & $\begin{array}{l}\text { Regardless } \\
\text { of rainfall }\end{array}$ \\
\hline
\end{tabular}

\subsection{Groundwater seepage field simulation}

The daily seepage field under various working conditions is calculated by the SEEP/W module, the groundwater in the slope decreases gradually with the 
decrease of the reservoir water level, the groundwater level in the slope is obviously convex, and the groundwater outlet is also higher than the reservoir water level, indicating that the groundwater decline rate lags behind the reservoir water level. Based on the analysis of the seepage field on the last day of each working condition (figure 8), with the increase of the decline rate of reservoir water, the groundwater level at the last moment gradually increases, but the increase shows a decreasing trend, indicating that with the increase of reservoir water level, the greater the hydrodynamic pressure in the slope is, the worse the stability of the slope is, but the decreasing range of the stability coefficient is weakening.

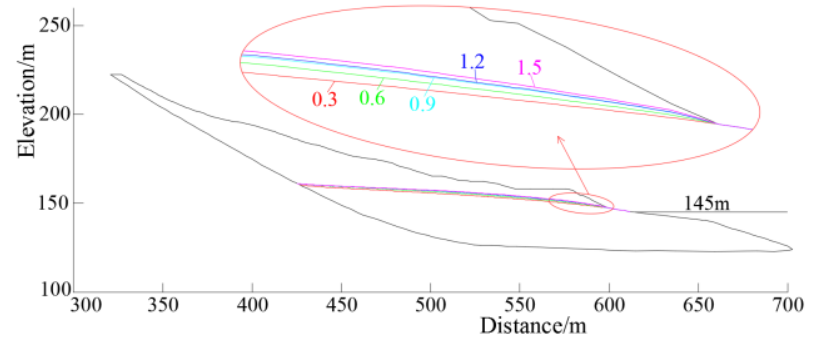

Fig. 8 Groundwater seepage field at different reservoir drawdown rate

\section{Results \& Discussion}

(1) Stability analysis of landslide

The overall analysis of figure 9 shows that with the decline of the reservoir water level, the stability of Baishuihe landslide gradually decreases, and its stability coefficient decreases by about $16 \%$; the impact of rainfall on Baishuihe landslide is limited, and the difference between rainfall and non-rainfall conditions is very small.

The existing monitoring data also show that the deformation of Baishuihe landslide is mainly caused by the decrease of reservoir water level. When the reservoir water is reduced from $175 \mathrm{~m}$ to $155 \mathrm{~m}$, the change is similar to the reservoir water dispatching model (figure 4), indicating that the stability coefficient of landslide is basically affected by the reservoir water level; when the reservoir water level is constant at $155 \mathrm{~m}$, the landslide stability coefficient increases gradually, and the increase is positively correlated with the stability time, with an increase of about $1.0-1.5 \%$, indicating that the constant reservoir water level is helpful to slow down the impact of rapid decline on landslides in the later stage.

When the reservoir water level accelerates from $155 \mathrm{~m}$ to $145 \mathrm{~m}$, the stability decreases gradually with the increase of the decline rate of the reservoir water level (condition A), and the stability coefficient of the condition Baue decreases by $14.8 \%-15.4 \%$. Compared with the normal decline condition A, there is a small decrease, a decrease of about $0.7 \%-1.2 \%$, indicating that increasing the decline rate of the reservoir water level has little effect on the stability of the landslide.

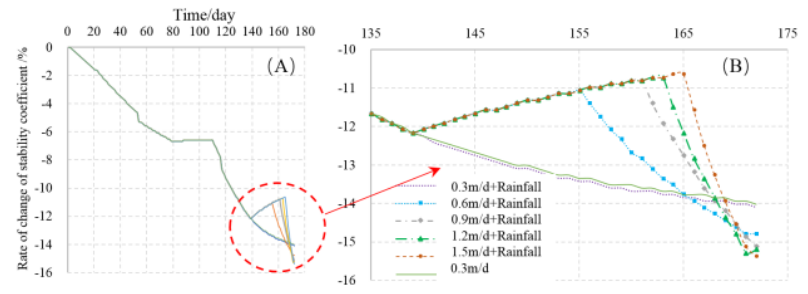

Fig. 9 Stability of Baishuihe landslide under different scenarios

(2) Analysis of reservoir water level dispatching mode.

The accelerated decline of reservoir water at the end is beneficial to the stability of the landslide. In the intermittent period of $155 \mathrm{~m}$ water level, the groundwater in the slope can fully dissipate, the hydrodynamic pressure decreases, and the stability of the landslide increases gradually, which is more beneficial to the stability of the landslide than the continuous decrease of reservoir water[7].

In the meantime, the effect of rainfall is not obvious enough. In the actual reservoir water dispatching, the reservoir water can be reduced to $155 \mathrm{~m}$ before the rainy season, so as to avoid the joint effect of reservoir water and rainfall on landslides. At the same time, the reservoir water is maintained above $155 \mathrm{~m}$ to the maximum extent, which can give better play to the benefits of the golden waterway.

From the point of view of hydrogeology, the accelerated decline at the end of the reservoir fully takes into account the adaptability of each elevation of the reservoir bank to the change of reservoir water. Because the immersion time of the reservoir bank below $155 \mathrm{~m}$ is the longest, fully reformed by the reservoir water, and the seepage pipe network in the slope is more developed[10], the groundwater in the slope can dissipate rapidly and can withstand the influence of the rapid rise and fall of the reservoir water.

From the dispatching analysis of the actual reservoir water level, it can also be confirmed that the reservoir bank can withstand the rapid rise and fall of reservoir water below $155 \mathrm{~m}$. Based on the analysis of the reservoir water dispatching curve in recent years $(180 \mathrm{~m} 240 \mathrm{~d}$ in figure 3), the annual flood season water rises from $145 \mathrm{~m}$ to more than $155 \mathrm{~m}$ in a short time, and then decreases rapidly to $145 \mathrm{~m}$, but it does not cause large-scale instability and deformation of the reservoir bank, indicating that the rapid drop of reservoir water from $155 \mathrm{~m}$ to $145 \mathrm{~m}$ has little effect on the stability of the landslide. In the long run, according to the adaptability of the reservoir bank to the reservoir water level change, the intermittent stable water level can be gradually increased, so as to give full play to the benefits of shipping and power generation.

\section{Conclusion}

(1) Baishuihe landslide is affected by the change of reservoir water level as a whole. When the reservoir water is reduced from $175 \mathrm{~m}$ to $145 \mathrm{~m}$, the stability coefficient of the landslide is reduced by about $15 \%$, and 
the influence of rainfall is limited. The monitoring data also show that the decline of reservoir water is the main factor leading to the deformation of the landslide.

Increasing the decline rate of the reservoir water level has a limited impact on the stability of the landslide, and the stability coefficient is reduced by about $0.7 \%$ $1.2 \%$.

(2) the method of accelerated decline at the end has comprehensive benefits. taking into account the adaptability of different elevations of the reservoir bank to the reservoir water level, the dispatching process of the reservoir water level is divided into two stages, and different descending rates are adopted according to local conditions. The model takes full account of disaster prevention and mitigation, shipping, flood control and power generation, and greatly prolongs the time of the water level of the reservoir above $155 \mathrm{~m}$, which is of great practical significance.

(3) In this paper, taking Baishuihe landslide as an example, considering precipitation and reservoir water level dispatching model, the landslide stability of Baishuihe landslide under different reservoir water level decline rates is studied, which has important guiding significance for guiding the dispatching of reservoir water level in the three Gorges reservoir area. This paper mainly studies the stability of Baishuihe landslide in the falling stage of reservoir water level, and then we can continue to study the stability of landslide under the condition of rising reservoir water level.

\section{Acknowledgments}

This work was supported by the science and technology project of State Grid (Research and Application of disaster Mechanism and Prevention Technology of large deformation of Tower Foundation in Salt Lake area, 522800210027).

\section{References}

1. Schuster RL. Reservoir-induced landslides. Bulletin of the International Association of Engineering Geology, 20, 8-15 (1979)

2. Crosta GB. Frattini P. Rainfall-induced landslides and debris flows-Preface. Hydrological Processes. 22, 473-7 (2008)

3. Huang Q. Wang J. Xue X. Interpreting the influence of rainfall and reservoir infilling on a landslide. Landslides 13, 1139-49 (2016)

4. Li W. Shi-mei W. Ling X. Coupling of Seepage and Stress of Shuping Landslide under the Combined Action of Reservoir Water Decline and Rainfall. Journal of Yangtze River Scientific Research Institute 31, 25-31 (2014)

5. Gui-rong Z. Wei C. Stability prediction for Bazimen landslide of Zigui County under the associative action of reservoir water lever fluctuations and rainfall infiltration. Rock and Soil Mechanics (S1), 476-82 (2011)
6. Peng W. Kunlong Y. Songsong M. Stability Analysis of Zhangjiacitang Landslide under Increased Daily Drawdown Rate of the Reservoir Level and Rainfall. Safety and Environmental Engineering 23, 36-42 (2016)

7. Zhi-yong X. Hua-feng D. Jian-lin L. An-Hong H. LI Chun-bo. De-long C. Influence of Intermittent Drawdown of Reservoir Water Level on the Stability of Accumulation Landslide. Journal of Yangtze River Scientific Research Institute 33, 1149 (2016)

8. Peng Z. Shu-jiang L. Cong-cong X. Mingliang Y. Seepage Flow and Stability Analysis of A Landslide under the Conditions of Water Level Fluctuation of Reservoir and Rainfall. Journal of Yangtze River Scientific Research Institute 32, 87-92 (2015)

9. Hongqu Z. Wu Y. Haifeng H. Junbao X. Analysis of Water Content and Stability of Reservoir Landslides with Different Rainfall Intensities. Safety and Environmental Engineering 23, 53-8 (2016)

10. Shang Y. Sun H. Hou L. Chen Y. Study on the stability of pebbly clay slopes with pipe drainage system. Chinese Journal of Rock Mechanics and Engineering 24, 1371-5 (2015)

11. Xianlong Y. Study on The Progressive Failure Probability of Baishuihe Landslide Under The Effect of Rainfall and Reservoir Water Fluctuation: China University of Geosciences (2016) 